\title{
O corpo nas atualizações do racismo contemporâneo
}

\section{The body in updated racism}

\author{
Viviane Castro Camozzato ${ }^{1}$
}

\begin{abstract}
RESUMO
Analiso o conceito de racismo a partir de suas relações com o tema dos discursos corporais e sua centralidade na produção dos sujeitos contemporâneos. Atravessa esta discussão a problemática de que o processo de investimento e valorização do corpo não pode ser apartado de todas as discussões suscitadas pelo crescente investimento sobre a vida advinda pelo biopoder - um poder que se pauta por "fazer viver e deixar morrer" e que também implica, no caso das discussões empreendidas neste artigo, em práticas racistas que envolvem a apartação dos nomeados como "diferentes" numa desenfreada busca pela "pureza", referida nas escritas analisadas como sendo uma característica de pessoas "magras" em oposição às "gordas". Discuto, portanto, a existência de atualizações do racismo no contemporâneo quando se trata de matar também pelas palavras, silêncios, julgamentos morais, em suma, pelas construções diferenciais dos "outros" em prol das referências identitárias.

Palavras-chave: corpo; norma; biopoder; racismo.
\end{abstract}

\begin{abstract}
I have analysed racism concept from its relationship with the body discourses and its centrality when making contemporary subjects. It is critical here that the process of investing and valuing the body cannot be separated from all discussions suggested by the growing investment on life coming from biopower - a power based on 'live and let die' and which, in the case of discussions analysed in this paper, also implies racist practices involving separating people as 'different ones' in an unbridled search for 'purity'

${ }^{1}$ Doutoranda em Educação pela Universidade Federal do Rio Grande do Sul (UFRGS). Membro do Núcleo de Estudos sobre Currículo, Cultura e Sociedade (NECCSO). Bolsista do Conselho Nacional de Desenvolvimento Científico e Tecnológico (CNPq )- Brasil.
\end{abstract}


referred to in the analysed writings as a characteristic for 'thin' people as opposed to 'fat' ones. So I have discussed the existence of updated contemporary racism, once it is also possible to kill with words, silence, and moral judgment; that is, through constructing the 'others' as different in the name of identity references.

Keywords: body; rule; biopower; racism.

Uma das características da sociedade ocidental, desde a Modernidade, refere-se à nomeação e posicionamento daqueles tomados como "outros" : seres culpabilizados por destoarem da normalidade criada, uma vez que suas diferenças (vistas como inatas) são postas como causadoras de todo o mal. Característica de um mundo que não prima simplesmente por excluir os "outros", mas, ao contrário, tende cada vez mais a delimitar o campo de ação desses "outros" como forma de melhor aproveitá-los, explicá-los, dizê-los, enfim, como forma de melhor conhecer para capturá-los. Cria-se, aí, um longo e infinito processo de criação de saberes - advindos da Pedagogia, Ciências da saúde, Psicologia, Educação física etc. - sobre os sujeitos para melhor controlá-los e dispor dos seus atos. Assim, em nosso mundo marcado pela criação de normas, parece haver certa naturalização dos valores inscritos na arena social, impossibilitando que, nas nossas tramas cotidianas, as categorias avaliativas utilizadas para ordenar e classificar os humanos sejam vistas como invenções datáveis e localizáveis dentro de certos regimes de verdade.

Nesse sentido, as normas - entendidas como saberes que funcionam como regras e que são, sempre, arbitrárias - parecem operar como uma eficaz máquina de diferenciação e de captura dos sujeitos. Com isso: a) criam-se saberes ao fabricar e veicular as formas "desejáveis" de estar sendo 3 sujeito; b) o poder-saber, ao desejar uma forma de ser sujeito busca subjetivar todos e a cada um, produzindo efeitos de verdade e, com isto, ensinando como "se deve ser"; c) quando a subjetivação se efetiva, resta, então, aos ditos "diferentes" guiarem-se pelas normas produzidas, a fim de buscarem a modificação de si mesmos - para serem aceitos e/ou aproveitados pelos demais. Esse efeito da norma (que, apesar de buscar ser único, nunca o é) prevê, também, a não aceitação das regras tidas como verdadeiras e únicas, como fica evidenciado nos

${ }^{2}$ Alterno, no decorrer do texto, o uso de "outros" (entre aspas) e outros. Isso se deve ao fato de que, quando falo em "outros", refiro-me àqueles que são marcados como "diferentes" em relação aos Mesmos. Nesse sentido, os outros (sem aspas) se referem a quaisquer outros.

${ }^{3}$ Como salienta Skliar (2003, p. 47): “A única alternativa possível para que a alteridade não fique aprisionada entre a condição e o estado do ser ou do não ser - ou do ser em parte - parece ser a de uma temporalidade que poderíamos denominar como a do estar sendo". 
inúmeros tipos de "anormais" criados: travestis, lésbicas, gays, surdos, obesos, loucos etc. Isto equivale a dizer que esse processo é complexo, pois mesmo que se busque "sair" do circuito cultural que tenta produzir a "mesmidade" se está, sempre, sendo constituído e ressignificado pelas leis da norma, que busca a ordenação do mundo. Afinal, "também o anormal está na norma, está sob a norma, ao seu abrigo. O anormal é mais um caso previsto pela norma. Ainda que o anormal se oponha ao normal, ambos estão na norma. É também isso que faz dela um operador tão central para o governo dos outros; ninguém escapa dela" (VEIGA-NETO, 2001, p. 115).

Desse modo, os saberes e poderes, situados e localizados numa determinada época, produzem determinados modos de existência. Dentro de tal entorno, situa-se um dos seres tomados recorrentemente como os "outros" de nosso tempo: as "gordas"4. Uma infinidade de saberes sobre elas são criados para que seja possível, cada vez mais, afastá-las da zona de estranheza, localizando-as na zona de anormalidade e, por uma mobilidade constante, aproximá-las - segundo a forma de "incluir para excluir" (VEIGA-NETO, 2001) - da zona de normalidade. A primeira zona mencionada refere-se ao que Bauman (1998) toma como "estranho", ou seja, aqueles seres que não possuem saberes sobre si, sendo desconhecidos dos saberes criados pelas Ciências, por exemplo, ou seja, seres sem conhecimentos sobre a sua "condição", sendo incógnitas e, por isso, "estranhos". Ser designado como "anormal", por sua vez, refere-se àqueles seres que possuem saberes sobre si, podendo ser nomeados como "outros" a partir de certos saberes específicos, isso porque as "operações de aproximação>conh ecimento>estranhamento, ou seja, inclusão>saber>exclusão" (VEIGA-NETO, 2001, p. 113) estão sendo realizadas. Ser "normal", todavia, alude à ideia de que tais sujeitos têm sobre si uma legitimação social por encarnarem a norma, sendo referência para os outros. Estar situado dentro da zona de normalidade, portanto, significa estar amparado por um conjunto de saberes que dizem, de antemão, "como se é", "o que se vale".

A respeito dessas considerações, cabe destacar as reflexões de Bauman (1998) ao argumentar que a Modernidade ancorou-se na tríade beleza (como a harmonia e perfeição entre as formas), pureza (enquanto a aniquilação da "sujeira") e ordem (como a busca de que cada coisa esteja em seu devido lugar e em nenhum outro) para se construir como civilização - compreendida como "a ordem imposta a uma humanidade naturalmente desordenada" (BAUMAN, 1998, p. 8) -, enquanto sinônimo para o termo Modernidade. A incessante busca

${ }^{4}$ Embora articule as discussões endereçando aos imperativos corporais que concernem às mulheres, é necessário salientar que os direcionamentos em relação aos homens não são algo nem um pouco desprezível nos discursos contemporâneos. 
pela efetivação desses ideais modernos, portanto, contribui para a criação de uma sociedade que, buscando um mundo linear, puro e ordenado, constrói o "outro" e, nesse mesmo movimento, muitas vezes, visa banir esse "outro" que passa a ser considerado a "sujeira" destoante. Como o referido autor aponta:

entre as numerosas corporificações da "sujeira" capaz de minar padrões, um caso [...] é de importância muito especial e, na verdade, única: a saber, aquele em que são outros seres humanos que são concebidos como um obstáculo para a apropriada "organização do ambiente"; em que, em outras palavras, é uma outra pessoa ou, mais especificamente, uma certa categoria de outra pessoa, que se torna "sujeira" e é tratada como tal (BAUMAN, 1998, p. 17, grifos do autor).

Embora se possa elencar uma infinidade de existências que corporificariam as marcas da "diferença", tornando-se a "sujeira" a ser extraída, ou mesmo modificada na sociedade, centro-me na questão dos corpos-"gordos" por compreender que as discursividades envolvendo o corpo têm se mostrado uma potente máquina de diferenciações. Além disso, a possibilidade de demarcação entre os "outros" e os Mesmos são efeitos de nossas relações com esses sujeitos. Deslocamento importante de ser realizado devido ao entendimento de que não é a "coisa", o sujeito que é "diferente", ou "estranho", "anormal", visto que eles reverberam os atributos construídos para marcar a nossa relação com eles. Em suma, processo de atribuição de valores sobre a "coisa", sobre cada sujeito e sua localização numa ordem social mais ampla, como é possível identificar na escrita a seguir, de uma comunidade do Orkut $t^{5}$ : "imagina ve sendo uma pessoa que cuida do corpo e talz, ai sai na rua e é obrigado a ver akelas gordas todas suadas, de calça d malhar ou mini saia bem curtinha, blusinha tomara q caia decotada a ponto dos peitos sairem rolando pela rua abaixo... pow, puta cena nojenta vey! akelas coxas toda furadinha, putz." . Assim:

${ }^{5}$ Site de relacionamentos criado em 22 de janeiro de 2004, e pertencente à empresa Google. Orkut também é o primeiro nome do projetista chefe desse serviço, cujo nome completo é Orkut Büyükkokten, de origem turca, e engenheiro da referida empresa. Cabe destacar, ainda, que os brasileiros são a maioria no Orkut. Em 30 out. 2009, às 12h15min, 51,26\% dos membros se identificavam como brasileiros - embora se creia que esse número possa ser maior, uma vez que muitos também preenchem o campo destinado à nacionalidade com outros países.

${ }^{6}$ Escrita datada em 10 set. 2005, na comunidade Eu odeio gordas que se acham, no tópico: Vocês deveriam odiar vocês mesmos. Cabe destacar, nesse momento, que as escritas disponibilizadas no decorrer desse artigo não foram revisadas, optando-se por deixar as marcas próprias de escrita dos sujeitos. 
A pureza é uma visão das coisas colocadas em lugares diferentes dos que elas ocupariam, se não fossem levadas a se mudar para outro, impulsionadas, arrastadas ou incitadas; e é uma visão da ordem - isto é, de uma situação em que cada coisa se acha em seu justo lugar e em nenhum outro. Não há nenhum meio de pensar sobre a pureza sem ter uma imagem da "ordem", sem atribuir às coisas seus lugares "justos" e "convenientes" - que ocorre serem aqueles lugares que elas não preencheriam "naturalmente", por sua livre vontade. O oposto da "pureza" - o sujo, o imundo, os "agentes poluidores" - são coisas "fora do lugar". Não são as características intrínsecas das coisas que as transformam em "sujas", mas tão-somente sua localização e, mais precisamente, sua localização na ordem de coisas idealizada pelos que procuram a pureza. As coisas que são "sujas" num contexto podem tornar-se puras exatamente por serem colocadas num outro lugar - e vice-versa (BAUMAN, 1998, p. 14, grifos do autor).

Em recorrentes escritas analisadas das comunidades do Orkut pesquisadas - refiro-me, especificamente, às comunidades Eu odeio gordas e Eu odeio gordas que se acham - é possível observar tais assertivas. Quando escrevem, por exemplo: "ser gorda até q vai, mas longe da gente, absurdo nos obrigar a ve aquelas banhas todas, eca!!!!!!!!!”’, ou mesmo: "Se situem GOOOOORDAS, vcs sujam a paisagem. [...] tem + é q desaparecer da face da terra ou então se mudara pra outro planeta"8. Logo, parece que até é possível continuar sendo do jeito que se está se os limites, as fronteiras - tão incessantemente produzidas e, também, burladas, felizmente - forem bem respeitadas, sem transgressões ou mesmo rupturas. Ou seja, sem possíveis misturas, incitando à mesmidade. Isso se trata da questão da localização e produção da "coisa" - mas de uma produção específica e situada nos discursos contemporâneos que, de um lado, valorizam a magritude e, de outro, penalizam a gorditude.

Sobre tal característica, Bauman (2003) nos alerta que os elementos principais da comunidade são a homogeneidade e a mesmidade. Desse modo, a mesmidade é questionada quando os "de fora" empurram as fronteiras - que são móveis - e irrompem nos espaços dos "de dentro", intensificando/ativando relações. No tempo presente temos, assim, a ativação desse processo, pois nosso mundo, marcado pela velocidade com que a informação se movimenta, torna

2005 .

${ }^{7}$ Comunidade Eu odeio gordas, no tópico Que nojo dessas gordas, escrita em 22 jan.

${ }^{8}$ Escrita presente na comunidade Eu odeio gordas, no tópico Que nojo dessas gordas, em 23 jan. 2005. 
cada vez mais complexo o controle de fluxos informacionais entre os que estão localizados dentro das comunidades. Desse modo, as fronteiras entre os "de dentro" e os "de fora" se tornam mais tênues. Essa movimentação é inerente ao processo de construção de comunidades contemporâneas, o que torna a ideia de unidade uma construção artificial e que, devido a isso, é buscada de forma bem intensa, por meio de lutas precisas e pontuais. Pensando nas comunidades, assim como na suposta unidade que pretendem adquirir, podemos ver o quanto a ideia de unidade comunitária é ficcional e, como ficção, é da ordem da construção. Supõe-se que todos os membros de tais comunidades aderem, de fato, a tais posicionamentos. Entretanto, nessas comunidades vemos conflitos, disputas, que se dão com outros membros que - muitas vezes intencionalmente - entram nesse tipo de comunidade para discutir/problematizar as escritas sobre os sujeitos expostos em questão. Comunidades que, portanto, não mostram apenas unidade, mas conflito, disputa. Nesse sentido, cabe ressaltar que qualquer pretensão de unidade é algo que precisa ser vigiado e defendido ad infinitum. Afinal, "a comunidade realmente existente se parece com uma fortaleza sitiada, continuamente bombardeada por inimigos (muitas vezes invisíveis) de fora e freqüentemente assolada pela discórdia interna" (BAUMAN, 2003, p. 19, grifos do autor.).

Segundo essa noção de Bauman (2003), comunidade significa mesmice, que é a ausência do outro, "especialmente um outro que teima em ser diferente, e precisamente por isso capaz de causar surpresas desagradáveis e prejuízos" (p. 104, grifo do autor). Esse "diferente" é corporificado numa variedade de "tipos" humanos que causam estranheza e insegurança, afirmação e fixação identitária. É a diferença que incomoda pela sua ambiguidade, pela sua condição de ser palpável - embora não palatável - e, portanto, capaz de se espalhar em nós/por nós. A diferença, encarnada nos "diferentes", é o que nos ronda, o que se torna uma ameaça constante. As "gordas", nesse caso, talvez sejam o exemplar dos mais perversos de aonde pode chegar a nossa (falsa) humanidade, transformada em desumanidade, pois elas são, recorrentemente, marcadas como alvos preferenciais de uma miríade de práticas de discriminação, alçadas ao foco constante das gozações, à penalidade por não se encaixarem nos rígidos padrões corporais que imperam na sociedade. Isso ocorre de modo frequente nas comunidades estéticas - as quais visam à uniformidade e adequação -, pois se vê a separação entre "a homogeneidade dos de dentro, em contraste com a heterogeneidade dos de fora." (BAUMAN, 2003, p. 105, grifos do autor).

Importa destacar ainda, como afirma Silveira (2002), que: "Os textos são produzidos a partir de discursos e de linguagens [...] que não apenas (e não principalmente) 'expressam' e 'comunicam' - como as análises clássicas das funções da linguagem nos ensinavam - mas também 'constroem'e 'constituem' a realidade" (p. 19). Quero reiterar nesse momento que as escritas expostas 
nesse artigo encontram condições de possibilidade para existir numa sociedade em que as diferenças são diariamente produzidas em meio a discursos e linguagens. Afinal, o ódio às pessoas nomeadas como "gordas", por exemplo, não é algo intrínseco aos sujeitos, algo da ordem da naturalidade, mas efeito de um processo social em que o considerado destoante das normas legitimadas é inquirido, visibilizado e julgado em relação ao dito padrão, normal. É assim que essas escritas, legitimadas por condições para expor e julgar os "outros", são construídas nas contingências macrossociais que nos atravessam.

Tratando das comunidades do tipo "eu odeio", presentes no Orkut, cabe salientar o uso de estratégias para burlar grupos de justiceiros que apagam comunidades difamadoras nesse site de relacionamentos, ou mesmo estratégias adotadas por tais grupos para burlar as investigações da Polícia Federal para indiciar pessoas "preconceituosas" na web. Isso se deve, entre outras coisas, pela ideia do politicamente correto que prega "harmonia" entre os ditos "diferentes" e os "não diferentes". O politicamente correto, então, não propicia que haja uma desestabilização das produções diferenciais do "outro", sendo visto como uma estratégia que se assemelha à tolerância, ou seja, as palavras mudam de nome, no entanto, a sua produtividade diferencial continua latente. Desse modo, a discriminação em relação às "gordas" tem continuidade, sendo algo aceito sem maiores questionamentos, afinal, supõe-se que "só é gordo quem quer". Posicionamentos como esses são, muitas vezes, postos como uma brincadeira - geralmente aceita e referendada - ou mesmo como uma possibilidade de exercitar a "liberdade de expressão": "q merda a opiniao é minha e acabou...tenho direito de expressar ela...liberdade de expressaoooo minha caraa.. a ditadura ja acabou..". ${ }^{9}$ Ou ainda: "Isso aqui eh um país livre e todo mundo tem direito de expressar o que acha..."10.

Assim, comunidades como Eu odeio gordas - nome que direciona à ideia de que odeia "gordas" em geral - acabam sendo excluídas e outras entram em seu lugar, como a Eu odeio gordas que se acham, que em lugar do tom generalizado situa o tipo específico - entre os muitos expostos - de "gordas" que eles odeiam. Como os excertos a seguir corroboram:

Tópico: Ganham o que com essa comunidade??

12/01/2006 09:04 SÓ PODE ESTAR LOUCA!!!! EM MOMENTO ALGUM COGITOU-SE DESCRIMINAÇÃO DE GORDINHAS...

${ }^{9}$ Excerto extraído da comunidade Eu odeio gordas que se acham, no tópico Vocês deveriam odiar vocês mesmos, escrito em 09 ago. 2005.

${ }^{10}$ Extraído do tópico Vou denunciar a comunidade..., na comunidade Eu odeio gordas que se acham. Escrita datada de 04 dez. 2005. 
APRENDE A INTERPRETAR A FRASE E ENTENDA QUE ESSA COMUNIDADE FALA DE GORDAS QUE SE ACHAM E NAO APENAS DE GORDAS!!!!!! TE LIGA!!!

Tópico: Vocês deveriam odiar vocês mesmos 03/09/2005 16:18 Essa comunidade é EU ODEIO GORDAS QUE SE ACHAM, não é EU ODEIO GORDAS, jah tive namoradas gordinhas e nem ligo, agora!!! Coisa horrorosa e a pessoa ser gorda e querer usar mini-saia com a perna cheio de celulites que até parem conjunto de furunclos e passearem na rua, assim como ir à praia de biquine fio dental.. Entende?? Quem faz o gordo ficar mal na fita são os próprios!!

Essa foi uma estratégia que visualizei a partir da criminalização de alguns escreventes em comunidades que endereçam a preconceitos de tipos variados. Desse modo, mudam-se as palavras, mas os sentidos continuam os mesmos, evidenciando um travestismo discursivo "onde os discursos sociais se revestem com novas palavras, se disfarçam com véus democráticos e se acomodam sem conflito às intenções dos enunciadores do momento" (DUSCHATZKY; SKLIAR, 2001, p. 119). Tal travestismo pode ser relacionado, ainda, ao racismo cordial, o qual se reveste em palavras supostamente mais brandas, ou mesmo na negação verbal de algo, mas não cessa de ser construído, evidenciando apenas um "apagamento" que é provisório.

Além do mais, quando os nomeados como "outros" são relacionados como sinônimo do que é tido como "sujeira", "impureza", produz-se, assim, como efeito dessa produção diferencial sobre esses sujeitos, um grave problema em que se discute e decide sobre a vida e a morte desses "outros". Sujeitos que são narrados, marcados, explicados, julgados, como os excertos destacados da comunidade Eu odeio gordas que se acham, no tópico Gorda merece viver?, parecem salientar:

21/11/2005 14:25 ai gorda tem mais é q morrer mesmu.. ja q nao soube cuidar da vida $q$ lhe foi dada!! esse bando de suina imbecil q se acham.. ve ja viram como sao as gorda?? pq todas elas sao todas falsas e gostam d fingir de felizes e se achar engraçadas? tem mais é q morrer do coração porra!! são apenas anomalias assim como esses gays q gostam de se fazerem de coitadinhos e defenderem as obesas!! gorda é lerda nao sabe fazer nada direito.. 
nem trabalhar sao lentas como o tamanho da merda q saem de seus cús como esgotos entupidos!! EU ODEIO GORDAS E VIADOS (VOU PEGAR TUDO NA PORRADA.. ESSES FDP) !!!

21/11/2005 14:31 essas merdas estão reclamando demais!! dá licença, monte de banha que sempre vem com a mesma desculpa, falta vergonha na cara, em vez de ficar postando aqui, vai fazer exercícios, brincar com o cachorro, se divertir, agora... ficar reclamando da vida aqui hahaha pra ve ver, nós somos tão insignificantes pra elas né... pois é, elas se ofendem, então são mais insignificantes ainda hahahahahaahah! é foda

\begin{abstract}
21/11/2005 16:27 POR SER UM PRIMATA. AHUAHUAHUAHUAHU PORQUE PRETO PRA MIM E PRIMATA PRIMO DE PRIMEIRO GRAU DO MACACO, ODEIO PRETO QUE SE ACHA PRETO CATIGUENTO PRETO TEM QUE MORRER TODO.....
\end{abstract}

22/11/2005 04:40 Para de falar mal de preto, ele nasceu preto e nao atrapalha ninguem, pelo contrario, sao gente boa $\mathrm{d}+$, agora vcs gordas nao, vcs enxem o saco, atrápalham com o visual e com a inveja, gordas vao virar sabao.

22/11/2005 05:13 é a escória da humanidade as gordas....mal amadas

"Não sabem cuidar de si”, são "anomalias", "lerdas", "não fazem nada direito", não têm "vergonha na cara", "não praticam exercícios", o seu visual "atrapalha", são "invejosas"... Em suma, as "gordas" - assim como outras "categorias" de humanos, como os excertos apontam - são narradas de modos depreciativos, pois elas "atrapalham", não se "encaixam" no modelo de sociedade apregoada nos variados tempos e espaços contemporâneos. A sua localização, portanto, em uma sociedade que alça ao corpo a função de atestar aquilo que se $e ́$, ou seja, julgamentos morais que se dão pela aparência, as 
produz como seres que "atrapalham", não se encaixam num mundo que almeja ordem, beleza e pureza. Com a sugestiva indagação "Gorda merece viver?", os sujeitos-escreventes desse tópico tratam de definir se a "categoria" (de pessoa (?), de animal (?) - que raça é essa?) "gorda" faz jus a continuar habitando esse mundo que, para esse determinado grupo comunitário, "pertence" às pessoas "magras" e, portanto, "normais":

essa sua cara horroroza, voce é oq ha de mais feio no mundo, voce é gorda, cara de piranha drogada, feia demais, e ainda se acha e vem defender essa tua raça de merda, voce é um erro da natureza [...] como o pessoal todo ja disse voces são bizarras demais, cria vergonah nessa tua cara! por favor pra voce e pras outras pessoas aqui! se possivel, se mata...pra voce é a melhor solução! ${ }^{11}$

Quando referi, anteriormente, que se trata de decidir sobre a vida e a morte dos “outros", esclareço que "por tirar a vida não entendo simplesmente o assassínio direto, mas também tudo o que pode ser assassínio indireto: o fato de expor à morte, de multiplicar para alguns o risco de morte ou, pura e simplesmente, a morte política, a expulsão, a rejeição, etc.” (FOUCAULT, 1999, p. 306). No caso das escritas de comunidades do tipo "eu odeio" que analiso nesse artigo, trata-se de matar por intermédio das palavras, pois, afinal, não se trata de matar a alteridade quando a silenciamos, quando alçamos os sujeitos ditos "diferentes" à impureza, quando, enfim, os produzimos como um objeto que serve, apenas, para reafirmar a nossa identidade ou mesmo a comunidade que pertencemos?

Dentro do contexto exposto, é possível afirmar que o racismo atualiza-se - através de práticas que gravitam em torno do "eu odeio" e, ainda, por um autocentramento em práticas de bioascese contemporâneas ${ }^{12}$ (ORTEGA, 2002), as quais borram, e algumas vezes até interditam, relações éticas com os outros - e, com isso, faz uso de novas e diferentes estratégias. O que parece estar em evidência são, portanto, "múltiplas formas de racismo que não por isso deixam de ser menos trágicas, menos macabras, menos humanas" (SKLIAR, 2004, p. 71). Mas é preciso indagar: “Com efeito, que é o racismo? É, primeiro, o meio

${ }^{11}$ Tópico Vou denunciar a comunidade..., na comunidade Eu odeio gordas que se acham, escrita em 02 dez. 2005.

${ }^{12}$ Práticas que se articulam na produção de assujeitamento e disciplinamento, ao contrário, por exemplo, da ascese grega analisada por Foucault (2004), em que o objetivo primordial estava em operar uma transformação de si que não ocorria exclusivamente pelo corpo, como na bioascese. 
de introduzir afinal, nesse domínio da vida de que o poder se incumbiu, um corte: o corte entre o que deve viver e o que deve morrer." (FOUCAULT, 1999, p. 304). O racismo, assim, parte da demarcação de "quem são os mesmos" para inventar "quem são os 'outros"'. Separação, apartação, construção de fronteiras simbólicas e materiais. O movimento de criar fronteiras e, com isso, erigir sólidas e potentes estratégias de nomeação dos estrangeiros, dos párias, é uma possibilidade de se pensar o racismo, visto que se trata do "fechamento" das fronteiras aos outros distantes em contraposição à abertura das fronteiras aos outros próximos. Ou seja, apartar a figura do outro incontornável, irreparável, inassimilável, e aproximar o outro que é próximo e, nesse escopo, munir-se da estratégia de fazer do outro radical um outro próximo, à sombra da Identidade-referência.

O racismo proclama, assim, uma morte que nos é anunciada cotidianamente, visto que "não há nada na nossa cultura que nos permita pensar e fazer com que o racismo desapareça, já que todo o movimento, todas as ações da nossa cultura estão dirigidas a uma violenta construção diferencial do outro; este processo leva à produção de uma cultura racista" (SKLIAR, 2004, p. 75). Embora o racismo seja algo que discursos que se dizem democráticos intentem "contornar", ele é algo que, também, a contemporaneidade não cessa de instigar e incitar através de fabricações diferenciais sobre o "outro". Ora, quando se estabelecem classificações e, por consequência, comparações, tendo em vista parâmetros classificatórios, o que se está erigindo é a produção do racismo numa cultura que se veste com véus supostamente democráticos, mas que não cessa a diferenciação entre nós e eles, entre eles e nós, fixando fortemente, novamente, as fronteiras. "A questão é que a alteridade começa a estar ausente, começa a faltar, e resulta ser imperiosamente necessária a produção construtiva do outro como diferença." (SKLIAR, 2004, p. 74). Trata-se, assim, de um processo intenso de construção social que ocorre em múltiplos espaços pelos quais circulamos e aprendemos a lidar conosco e com os outros.

Retomando os excertos expostos anteriormente, um dos sujeitos-escreventes da comunidade Eu odeio gordas que se acham expressa que: "ai gorda tem mais é q morrer mesmu.. ja q nao soube cuidar da vida q lhe foi dada!! [...] tem mais é q morrer do coração porra!! são apenas anomalias". Parece-me que tais assertivas endereçam à ideia de que as "gordas", no caso, ao não terem sabido "cuidar da vida q lhe [s] foi dada", transformam-se em outra raça, algo que as afasta da ideia uniformizada de sermos, todos, e finalmente, humanos. Sendo consideradas "anomalias", como foi exposto na escrita destacada anteriormente, então as "gordas" seriam uma raça à parte, não humana, mas algo que, por destoar do "normal", inscreve-se em uma classificação outra. Raça, nesse sentido, refere-se a "Grupo humano que supostamente se distinguiria de 
outros por apresentar características físicas, biológicas ou genéticas homogêneas." (SILVA, 2000a, p. 95). E as "gordas" distinguem-se por possuírem uma "obesidade que é obscena, porque traduz a sobra, o excedente, tudo aquilo que no corpo se tornou demais" (COUTO, 2001, p. 178) e, ainda, por serem biológica e geneticamente dissonantes da norma, mas homogêneas em relação a outros "anormais" de sua categoria, ou melhor, de sua pretensa "raça".

A esses sujeitos caberia, assim, a morte, enquanto possibilidade de "limpar" o mundo do que "suja" a paisagem, do que incomoda por não ser a imagem espelhada do "eu". Processo esse que ocorre concomitantemente com a necessidade desse "outro" para a produção de si, ou seja, nos agrupamentos comunitários o "outro" é presença constante para criar a ideia de uniformidade dos que estão dentro da comunidade.

Sobre tais questões é pertinente considerar, ainda, que "racializar um grupo, um indivíduo, um país, uma comunidade, uma raça etc., é o ato de $m a$ tar mais cedo ou mais tarde - e sobretudo mais cedo, como estamos assistindo hoje." (SKLIAR, 2004, p. 72, grifos do autor). E racializar passa, assim, pelos significados atribuídos aos corpos, os quais produzem classificações a partir de características que individualizam e, ao mesmo tempo, homogeneízam um corpo em relação aos demais. As "gordas", nesse sentido, são tomadas como uma outra raça, incluindo-se nas (cruéis) estratégias do racismo: discriminação, segregação, preconceito e violência (SKLIAR, 2004).

A comunidade do Orkut "Eu odeio gordas", por exemplo, era situada no eixo indicado para a discussão sobre animais em geral. Desse modo, questiono: as "gordas" não são consideradas nem como subumanas, mas como pertencentes a outro grupo, os animais? Não são humanas de nenhuma espécie? Ou seriam humanas de outra espécie? Haveria os "altos" humanos, aqueles que decidem sobre a vida e a morte dos "baixos" humanos, aqueles que viveriam às margens, esgueirando-se entre uma impossibilidade e outra? "Tratar-se-ia, portanto, de 'seres abjetos', eventualmente excluídos até da própria categoria de sujeitos. De certo modo, tais criaturas estariam no limiar da humanidade, sempre ameaçadas de caírem no domínio das monstruosidades e das aberrações." (SIBILIA, 2004, p. 74).

Se a questão da raça associa-se às demarcações operadas a partir de características físicas, biológicas e genéticas, como comentado, cabe destacar, ainda, que:

No contínuo biológico da espécie humana, o aparecimento das raças, a distinção das raças, a hierarquia das raças, a qualificação de certas raças como boas e de outras, ao contrário, como inferiores, tudo isso vai ser 
uma maneira de fragmentar esse campo do biológico de que o poder se incumbiu; uma maneira de defasar, no interior da população, uns grupos em relação aos outros. (FOUCAULT, 1999, p. 304).

A primeira função do racismo é, nesse sentido, "fragmentar, fazer cesuras no interior desse contínuo biológico a que se dirige o biopoder." (FOUCAULT, 1999, p. 305). Uma apartação do tipo biológico, o que possibilita que um grupo heterogêneo da sociedade - a população - seja subdividido em uma miscelânea de raças, ou melhor, significa subdividir a espécie em subgrupos, o que é nada mais que a produção de raças. No caso desse artigo temos, assim, mulheres que são subdivididas em "magras" ou "gordas", cada uma com operações diferenciais sobre si a partir de suas características físicas.

A segunda função do racismo será possibilitar uma relação positiva, consistindo numa afirmação da Identidade de uma raça em relação à(s) outra(s) raça(s). Ou seja, referendação da ideia de que "quanto mais você deixar morrer, mais, por isso mesmo, você viverá” (FOUCAULT, 1999, p. 305). O racismo consente que as relações diferenciais entre as raças sejam do tipo biológico, ou seja: "quanto mais as espécies inferiores tenderem a desaparecer, quanto mais os indivíduos anormais forem eliminados, menos degenerados haverá em relação à espécie, mais eu - não enquanto indivíduo, mas enquanto espécie - viverei, mais forte serei, mais vigoroso serei, mais poderei proliferar" (FOUCAULT, 1999, p. 305). Nesse sentido: "A morte do outro não é simplesmente a minha vida, na medida em que seria minha segurança pessoal; a morte do outro, a morte da raça ruim, da raça inferior (ou do degenerado, ou do anormal), é o que vai deixar a vida em geral mais sadia; mais sadia e mais pura." (FOUCAULT, 1999, p. 305).

Trata-se, pois, de uma relação biológica, de eliminar as impurezas, sanar os desvios. Ora, se numa sociedade da normalização ${ }^{13}$, onde "se cruzam, conforme uma articulação ortogonal, a norma da disciplina e a norma da regulamentação" (FOUCAULT, 1999, p. 302), o fazer viver é alçado às alturas, extrair a vida nesse sistema somente é aceitável se tratar da "eliminação do perigo biológico e [do] [...] fortalecimento, diretamente ligado a essa eliminação, da própria espécie ou da raça. A raça, o racismo, é a condição de aceitabilidade de tirar

${ }^{13}$ Compreendo a normalização, juntamente com Silva (2000b, p. 83), como "um dos processos mais sutis pelos quais o poder se manifesta no campo da identidade e da diferença. Normalizar significa eleger - arbitrariamente - uma identidade específica como o parâmetro em relação ao qual as outras identidades são avaliadas e hierarquizadas. Normalizar significa atribuir a essa identidade todas as características positivas possíveis, em relação às quais as outras identidades só podem ser avaliadas de forma negativa." 
a vida numa sociedade de normalização" (FOUCAULT, 1999, p. 306). Como referi anteriormente, a partir da citação de Foucault, tirar a vida é uma operação que pode se dar através de dois processos: um assassínio direto e/ou um assassínio indireto. Muitos dos excertos que venho expondo, os quais se referem ao racismo em operação nas relações diferenciais com o "outro", agem para tirar a vida, para expor à morte por intermédio de palavras escritas, as quais, acredito, produzem efeitos bem concretos, incidindo nos modos de dar forma à vida tanto dos sujeitos-escreventes dessas comunidades quanto dos leitores (mesmo que ocasionais) dessas mesmas comunidades e, ainda, dos sujeitos que são o alvo privilegiado dessas agregações.

Se assistimos a uma crescente centralidade de discursos corporais, se o que envergonha é ter um corpo dissonante do modelo mais apregoado, que atualizações na forma do racismo temos? Como frequentemente é salientado, o corpo é o alvo privilegiado de um conjunto de práticas: quando discorremos sobre sexualidade, moda, identidades juvenis, entre outros, o corpo está aí, espreitando o conjunto de processos que nos tornam sujeitos de certas experiências. Desse modo, o corpo constantemente é (re)avaliado, comparado, selecionado. Se, ainda, o racismo atua através da desqualificação da dita "raça ruim" para poder exercer o seu "direito" de matar - em prol de deixar o mundo mais ordenado, puro, belo e higiênico para a continuidade da segurança Identitária -, então agora - e talvez há muito tempo - a questão do corpo ruim, do corpo impuro, do corpo maligno, do corpo inassimilável, do corpo monstro, do corpo incontrolável..., aparece como alvo central nas tentativas de remodelar a espécie humana. Como salienta Foucault (1999, p. 307), "cada vez que houve um enfrentamento, condenação à morte, luta, risco de morte, foi na forma do evolucionismo que se foi forçado, literalmente, a pensá-los."

Tal contexto, parece-me, configura-se como uma das condições de possibilidade para as constantes modificações corporais, as quais associam-se a uma colonização interna do corpo. "A tecnologia invade o corpo para acelerá-lo. Todas as técnicas de mecanização e instrumentalização da corporalidade, as próteses externas, internas, informáticas ou genéticas, visam a essa excitação contínua." (COUTO, 2001, p. 186, grifos meus). Visam, também, a uma "qualificação" contínua da materialidade corpórea, uma vez que pelo evolucionismo Darwiniano tal qualificação não obedeceria à lógica da aceleração e excitação contínuas apontadas por Couto (2001). Qualificar, melhorar, limpar, extrair, ordenar, purificar, acelerar, modificar, enfim, verbos que atendem a um desejo eugênico, pois "Quando for preciso matar pessoas, matar populações, matar civilizações, como se poderá fazê-lo, se se funcionar no modo do biopoder? Através dos temas do evolucionismo, mediante um racismo." (FOUCAULT, 1999, p. 307). 
$\mathrm{Na}$ esteira de tais considerações, cabe salientar, por fim, o quanto a já destacada atualização do racismo desenvolve-se a partir de modificações que engendram outros modos de ver a vida e a morte, incidindo, ainda, nos modos de intervir na vida no escopo das transformações que conduziram do "deixar viver e fazer morrer" da sociedade de soberania para o "fazer viver e deixar morrer", nas sociedades biopolíticas (FOUCAULT, 1999). Na teoria clássica da soberania o foco era deixar viver e fazer morrer: "O efeito do poder soberano sobre a vida só se exerce a partir do momento em que o soberano pode matar." (FOUCAULT, 1999, p. 286). Tenho visto, nesse sentido, que muitos sujeitos das comunidades do tipo "eu odeio" - muitos nomeadores das "outras-gordas" - se autointitulam, de certo modo, como soberanos, dotando-se do direito de apontar o "outro", o que é um jeito de matá-lo continuamente. Os aspectos apontados parecem marcar, assim, modos contemporâneos (e por que não, perversos?!) de matar continuamente os sujeitos produzidos como "outros". Frente às constantes atualizações do racismo importa, como estratégia política e ética, problematizar infinitas vezes as questões: "o que estamos fazendo de nós mesmos?", "o que estamos fazendo com os 'outros'?”.

\section{REFERÊNCIAS}

BAUMAN, Z. O mal-estar da pós-modernidade. Rio de Janeiro: Jorge Zahar, 1998. . Comunidade. Rio de Janeiro: Jorge Zahar, 2003.

COUTO, E. S. A satelização do corpo: uma estratégia pós-humana de sobrevivência. In: SILVA. D. F.; FRAGOSO, S. (Orgs.). Comunicação na Cibercultura. São Leopoldo: Unisinos, 2001. p. 167-190.

DUSCHATZKY, S.; SKLIAR, C. O nome dos outros. Narrando a alteridade na cultura e na educação. In: LARROSA, J.; SKLIAR, C. (Orgs.). Habitantes de Babel: políticas e poéticas da diferença. Belo Horizonte: Autêntica, 2001. p. 119-138.

FOUCAULT, M. Aula de 17 de março de 1976. In: FOUCAULT, M. Em defesa da sociedade: o curso no Collège de France (1975-1976). São Paulo: Martins Fontes, 1999. p. 285-315.

. A hermenêtica do sujeito. São Paulo: Martins Fontes, 2004.

ORTEGA, F. Da ascese à bio-ascese ou do corpo submetido à submissão ao corpo. In: RAGO, M.; ORLANDI, L. B. L.; VEIGA-NETO, A. (Orgs.). Imagens de Foucault e Deleuze: ressonâncias nietzchianas. Rio de Janeiro: DP\&A, 2002. p. 139-173. 
SIBILIA, P. O pavor da carne: riscos da pureza e do sacrifício no corpo-imagem contemporâneo. Revista FAMECOS, Porto Alegre, n. 25, p. 68-84, dez. 2004.

SILVA, T. T. Teoria cultural e educação - um vocabulário crítico. Belo Horizonte: Autêntica, 2000a.

.A produção social da identidade e da diferença. In: SILVA, T. T. (Org.). Identidade e diferença: a perspectiva dos estudos culturais. Petrópolis, RJ: Vozes, 2000b. p. 73-102.

SILVEIRA, R. M. H. Textos e Diferenças. Leitura em REVISTA, Ijuí, n. 3, p. 19-22, jan./jun. 2002.

SKLIAR, C. Pedagogia (improvável) da diferença: e se o outro não estivesse aí? Rio de Janeiro: DP\&A, 2003.

. A materialidade da morte e o eufemismo da tolerância. Duas faces, dentre as milhões de faces, desse monstro (humano) chamado racismo. In: GALLO, S.; SOUZA, R. M. (Orgs.). Educação do preconceito: ensaios sobre poder e resistência. Campinas: Alínea, 2004. p. 69-90.

VEIGA-NETO, A. Incluir para excluir. In: LARROSA, J.; SKLIAR, C. (Orgs.). Habitantes de Babel: políticas e poéticas da diferença. Belo Horizonte: Autêntica, 2001. p. $105-118$.

Texto recebido em 30 de outubro de 2009.

Texto aprovado em 03 de julho de 2010. 